\section{Perils of systematic reviews}

$\mathrm{J}$ eremy Grimshaw provides a useful report card on the first 10 years of the Cochrane Collaboration. ${ }^{1}$ In addition to showcasing its virtues, he describes existing gaps and outlines challenges for the future. However, Grimshaw did not discuss the perils of publishing a systematic review when no eligible studies can be found for inclusion.

A recent Cochrane review of support for women and families after a perinatal death $^{2}$ illustrates the problem. The authors of that review described the availability of data as "sparse" and "variable." None of the published studies met their quality criteria for inclusion. In their discussion, the authors appropriately identified the limitations of the study but then went on to conclude that the lack of trials was further complicated by "the provision of an empathic caring environment, and strategies to enable the mother and family to accept the reality of the death, as part of standard nursing and social support in most of the developed world." " However, the basis for that conclusion is questionable, and evidence exists to contradict the proposition. ${ }^{3-6}$ Indeed, among health care professionals, there contin- ues to exist a sense of discomfort with this subject matter that frequently spills over into the care provided, which is often inadequate and can actually be detrimental. $^{6}$

Conclusions from reviews that include no high-quality studies must be considered carefully and should be well substantiated by other evidence. Illinformed conclusions presented in the Cochrane database can have an important steering effect on both practitioners and researchers who use review findings.

\section{Ariella Lang}

CIHR Postdoctoral Fellow

Nancy Edwards

CHSRF/CIHR Nursing Chair

School of Nursing

University of Ottawa

Ottawa, Ont.

\section{References}

1. Grimshaw J. So what has the Cochrane Collaboration ever done for us? A report card on the first 10 years [editorial]. CMA7 2004;171(7):747-9.

2. Chambers HM, Chan FY. Support for women/families after perinatal death [Cochrane review]. In: The Cochrane Library; Issue 2, 2004. Oxford: Update Software.

3. Ujda RM, Bendiksen R. Health care provider support and grief after perinatal loss: a qualitative study. Illness Crisis Loss 2000;8(3):265-85.

4. Lasker JN, Toedter LJ. Satisfaction with hospital care and intervention after pregnancy loss. Death Stud 1994;18:41-64.
5. Covington SN, Theut SK. Reactions to perinatal loss: a qualitative analysis of the National Maternal and Infant Health Survey. Am 7 Orthopsychiatry 1993;63(2):215-22.

6. Lang A, Goulet C, Amsel R. Explanatory model of health in bereaved parents post-fetal/infant death. Int $\mathcal{F}$ Nurs Stud 2004;41:869-80.

DOI:10.1503/cmaj.1041715

\section{[The author responds:]}

A riella Lang and Nancy Edwards Acomment on a Cochrane systematic review of support for women and families after perinatal death. ${ }^{1}$ That review highlighted that although such support is now part of standard nursing and social practice in most of the developed world, there is little evidence to support or refute the perceived benefits of the intervention. The authors of the review also noted that this aspect of standard care raises practical issues for future randomized trials. Nevertheless, they concluded that "Methodologically rigorous trials are needed in order to assess whether it is worth spending additional resources on care provided by professionals with specialised skills in managing bereavement, in comparison to that available when good routine perinatal care is provided by normally skilled sensitive professionals." Lang and Edwards have identified a number of studies that appear to demonstrate 